\title{
The Effect of Compound Magnetic - Electrostatic Lenses Insulation on its Optical Properties
}

\author{
Alaa A. Ahmad \\ Department of Physics/ College of Science/ University of Mosul
}

(Received 30/6/2013;Accepted 9/9/2013)

\begin{abstract}
The present research work takes the intensive studies on two types of electron lenses (magnetic and electrostatic), in order to obtain the preferable design of a compound lens. The single polepiece magnetic lens models of the same dimension and different structure insulations (iron and air) have been designed and tested. It was found that the lens with iron insulation has been achieved better optical performance. Another study has been carried out on a set of asymmetrical electrostatic lenses having different geometries of the outer electrodes. It was found that the geometrical shape of the outer electrode has a clear effect on the electron optical properties. The electrostatic retarding lens was inserted inside the magnetic lens in front of the specimen due to improvement in the objective focal properties especially at low beam voltages. Furthermore, a good resolving power has been obtained from this type of the compound lens in comparison with that of the traditional pure magnetic lens. The result of the compound lens of the preferable design was compared with those of the published papers; it was found that both results are in good agreement with each other.
\end{abstract}

Keywords: Polepiece structure insulation, Low beam voltage, Asymmetrical electrostatic immersion lens, Compound lens design.

\section{تأثير العزل على الخواص البصربة في المسلت المغنليسية - الكهروستانتكية المركبة}

\section{المالضص - (المص}

يتناول البحث الحالي درلسة مكثقة لنوعن من العهست الالكترونية (المغنطيسية والكهروستاتيكية) للحصول على افضل

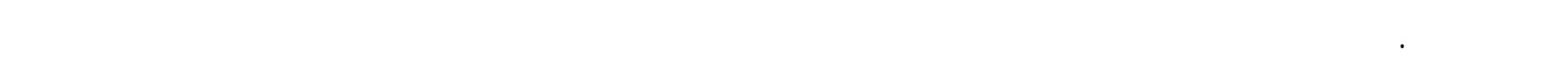

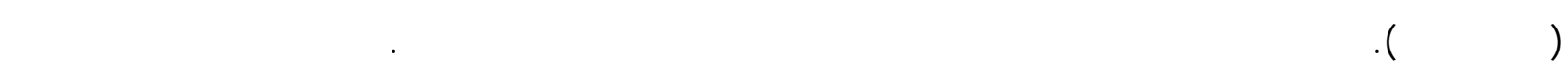

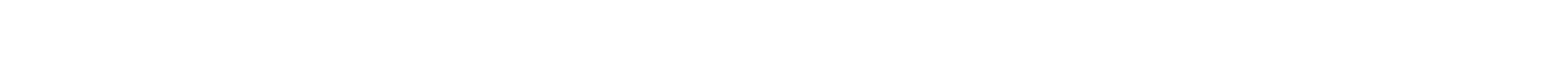
الهنهي للتطب الخارجي تأثيرا واضحا على الخواص البصرية الالكترونية. وعند وضع العهسة الكهروستاتيكية المعوقة دلخل

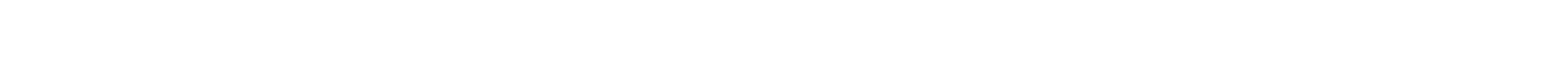
الالكترونية. فضلا عن ذلك مّ الحصول على قدرة تحلل جيلة لهذا النوع من العهلت المركبة مقارية مع العهسة المغنلطيسية

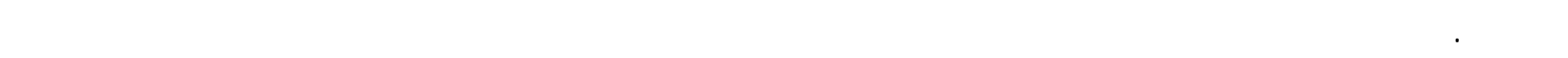
حديثا.

الكالمل الدالة: العزل في تركيب الثطب، الفولتية المنخفضة للحزمة، العهة الكهروستاتيكية اللمتناضرة المغمورة، تصميم العهة الالكترونية المركبة. 


\section{INTRODUCTION}

Low- voltage microscopy can produce high - resolution, high - contrast images of nanometerscale surface features. Several techniques exist for low- energy electron generation, but most successful in current instrumentation is the combination of a magnetic lens with an electrostatic immersion lens. This compound lens allows the low - voltage column to maintain high potential in the column while independently controlling the landing energy on the sample (Muray, 2011), in 1968, low- voltage operation of the scanning electron microscope (SEM) was achieved by employing Pease's principle, where he points out that an electrostatic retarding field in front of the specimen can further improve the optical performance of the purly magnetic probe forming systems. The advantages for which low- voltage operation of the microscope confer are an increase of the secondary electrons emission coefficiens, the reduced penetration of the primary electrons leads to the effects due to the surface layers of the specimen and the ability to examine the insulating materials without charging the artifacts occurring in the images (Tromp, 2000).

The configuration of the compound lens consists of the magnetic lens with an electrostatic immersion lens placed behind the specimen called "Gemini objective lens" was firstly applied by Frosien (Frosien et al., 1989). A high performance SEM 's from Carl Zeiss, which has been developed under license to ICT Gmbh (Drexel et al., 1994). The invention is to observe semiconductor wafers with higher resolution at a low acceleration voltage in particular, achieving such high-resolution observability when a wafer is inclined or tilted at large angles by Yonezawa (Yonezawa et al., 2003). LEO 982 FESEM can also operate at an accelerating voltage ranging from $0.2 \mathrm{kV}$ to $30 \mathrm{kV}$ and has the resolutions of $>4 \mathrm{~nm}$ at $1 \mathrm{kV}$ (Young, 2004). The new type of the electron lenses (compound lens), having an overlapping of the magnetic and electrostatic retarding fields concentrated inside the lens structure (Gemini lens). It is perfectly suitable as an objective lens for low- voltage SEM's, this lens was studied extensively by (Hujazie, 2006). A single polepiece magnetic lens with an electrostatic lens were designed and manufactured as a compound lens by (Al-Jumayli, 2010). Recently, Study on rotation - free combined immersion magnetic electrostatic lenses which can be used in projection electron beam lithography systems by (Jingyi Zhao et al., 2012)

The principal aim of this work is to achieve an improved design for the compound lens suitable for an objective lens. The first part of the present paper has tackled the influence of the insulation material in polepiece on the electron optical properties to the magnetic lens. The second part of the work is carried out to investigate the effect of the outer electrode geometry on the performance of an electrostatic lens and the third part is considered as a combination of the asymmetrical magnetic lenses which possess the preferable design previously obtained in part one with that of the asymmetrical two- coaxial cylindrical electrostatic lens of an external conical shape acquires the best lens design in part two. This combination of lenses are perfectly suitable as an objective compound lens for the low- voltage SEM which gives a good resolution at low beam energies.

\section{Lens Design Considerations}

\section{A. The Magnetic Electron Lens Design Considerations}

Two types of asymmetrical single polepiece lenses have been designed and have the same polepiece parameters, geometrical structure of the magnetic circuit and coil windings and with different structure insulations are used in their polepieces denoted by (Lens M1 and lens M2). A numerical calculation for the electron optical properties of magnetic lenses (M1 and M2) based on the finite element method which was first used by (Munro, 1975) and developed by (Lencova', 1986) and later by (lencova' and lenc, 1994) is based on a differential form in which the whole area is divided into finite elements.

The shape of the polepiece is taken in the form of a truncated cone of flat end cap. The polepiece of each type consists of two parts of iron shell overlap each other along the longitudinal polepiece direction separated by a small space of air, the schematic diagram of the cross- section of 
the two lenses are shown in Fig. 1(a and b). The outer part of polepiece region is filled with an insulating material of thickness $\mathrm{T}=5 \mathrm{~mm}$ either by an air as in (Fig. 1a), or by a soft iron as in (Fig. 1b).

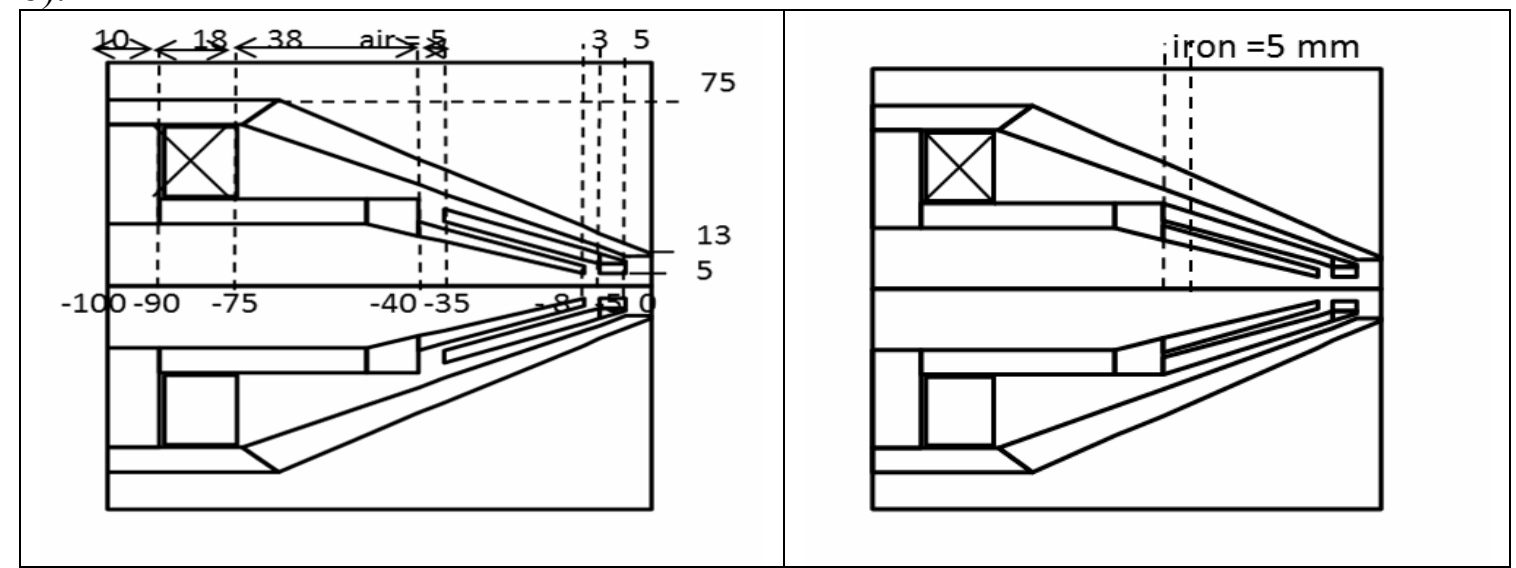

(a) Lens M1

(b) Lens M2

Fig. 1: Cross- section of the two types of single polepiece lenses have polepiecec structure insulation: (a) Air, (b) Soft iron.

Fig. 2 shows the axial magnetic flux density distribution $\mathrm{B}_{\mathrm{z}}$ along the optical Z-axis of the lenses $\left(M 1\right.$ and M2) calculated at the same excitation $(\mathrm{NI}=500 \mathrm{~A}-\mathrm{t})$. The values of $\mathrm{B}_{\mathrm{z}}$ are computed by the aid of program AMAG (Lencova', 1986) developed by (Al- Khashab and Ahmad, 2005) using the finite element method. It can be seen that the maximum value of $B_{z}$ obtained from the lens M2 with soft iron insulation is larger than that of the lens M1 with an air insulation occurred at $(\mathrm{Z}=5 \mathrm{~mm})$. Furthermore, The paraxial ray trajectory $\mathrm{R}_{\mathrm{z}}$ for the electron beam through a purely magnetic lens that enters the lens field parallel to the optical axis of both lenses M1 and M2 are computed as shown in (Fig. 3). This figure shows that lens M2 has a remarkable focusing effect than lens M1.

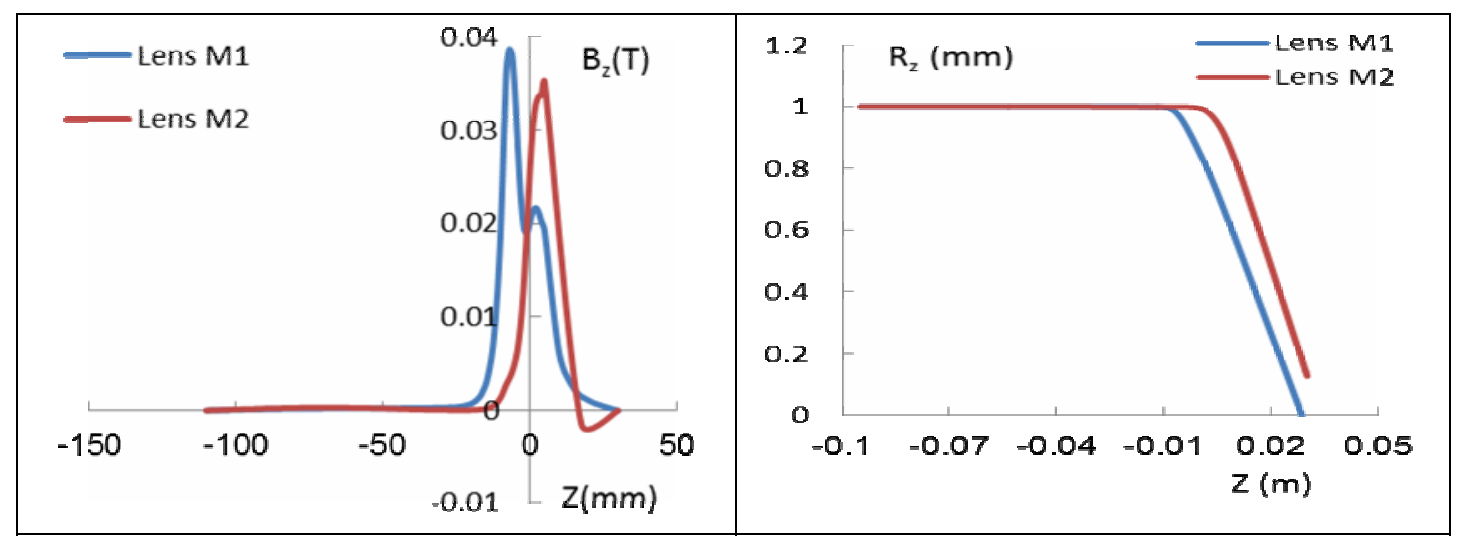

Fig. 2: Magnetic flux density distribution $B_{z}$ Fig. 3: Paraxial ray trajectory $R_{z}$ of the of lenses M1 and M2 as a function of distance (z). electron in the magnetic lenses M1and M2) as a function of distance (z).

The plot of the equipotential lines for the previous lenses (M1 and M2) are computed by the aid of flux program M31(Munro, 1975) modified by Murad (Murad, 1998). (Fig. 4 a and b) represents the flux lines trajectories of the lenses M1and M2. Where lens M1 filled with an air insulation as in (Fig. 4a), compared with lens M2 filled with soft iron insulation, as in (Fig. 4b). It is found that, the flux lines of lens M2 are more regular in shape and have the form of circular path concentrated round the pole region. It should be kept in mind that each lens obtained the same excitation in the coil windings $(\mathrm{NI}=500 \mathrm{~A}-\mathrm{t})$. 


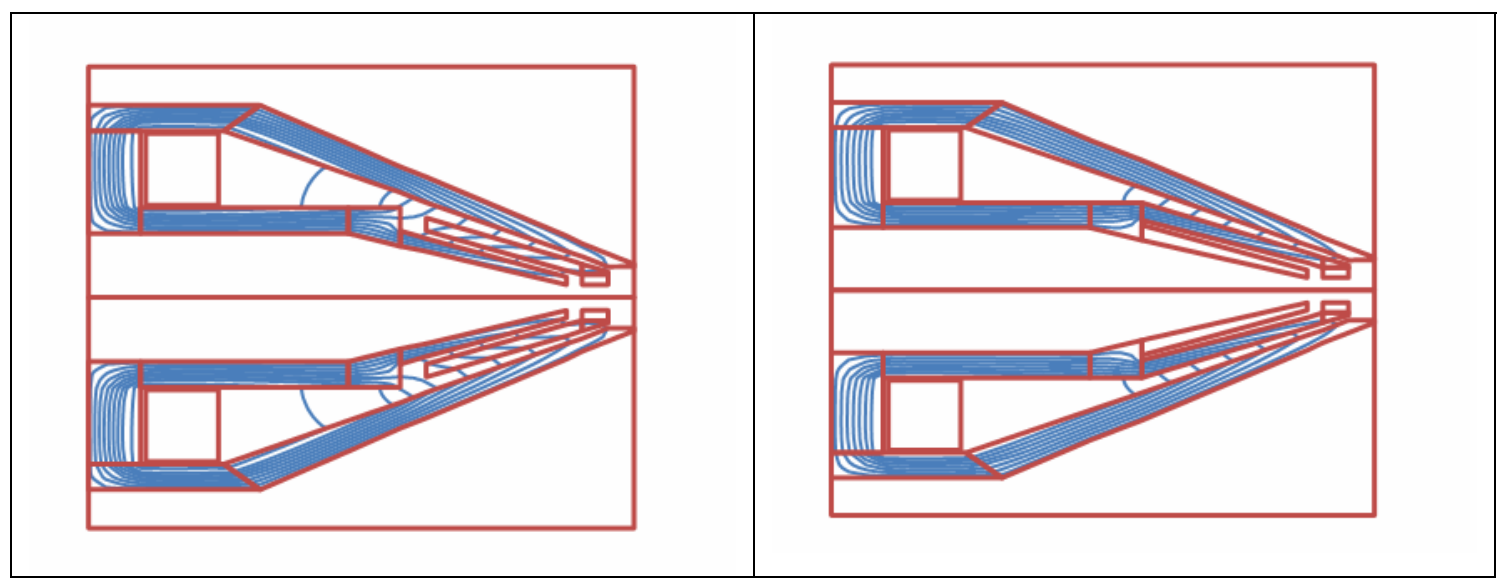

(a) Lens M1

(b) Lens M2

Fig. 4: Corresponding flux lines trajectories throughout the magnetic circuit of the lenses (M1 and M2) calculated at (NI=500 A-t) filled with :(a) air insulation; (b) soft iron insulation.

The required operating point of the lens varies with, e.g. the position of the specimen, the acceleration voltage of the electrons, and the required magnification (Van Bree et al., 2009) and the choice of a favorable lens design in an electron microscope depends on its objective focal properties (Mulvey, 1982). The important electron optical properties of the lens are the objective focal length $\mathrm{f}_{\mathrm{m}}$, spherical and chromatic aberration coefficients $\left(\mathrm{C}_{\mathrm{s}}\right.$ and $\left.\mathrm{C}_{\mathrm{c}}\right)$ respectively. (Fig. 5) illustrates the variation of the relative spherical aberration coefficients $\left(\mathrm{C}_{\mathrm{s}} / \mathrm{f}_{\mathrm{m}}\right)$ and the relative chromatic aberration coefficients $\left(\mathrm{C}_{\mathrm{c}} / \mathrm{f}_{\mathrm{m}}\right)$ for the magnetic lenses (M1 and M2) as a function of relativisticaly corrected accelerating voltage $V_{r}$. It is noticed that the results of $\left(C_{s} / f_{m}\right)$ of lens $M 2$ are smaller than that obtained from the lens $M 1$, also the values of $\left(\mathrm{C}_{\mathrm{c}} / \mathrm{f}_{\mathrm{m}}\right)$ of lens $\mathrm{M} 2$ are smaller compared to that of the lens M1 (Wen-ping et al., 2009).

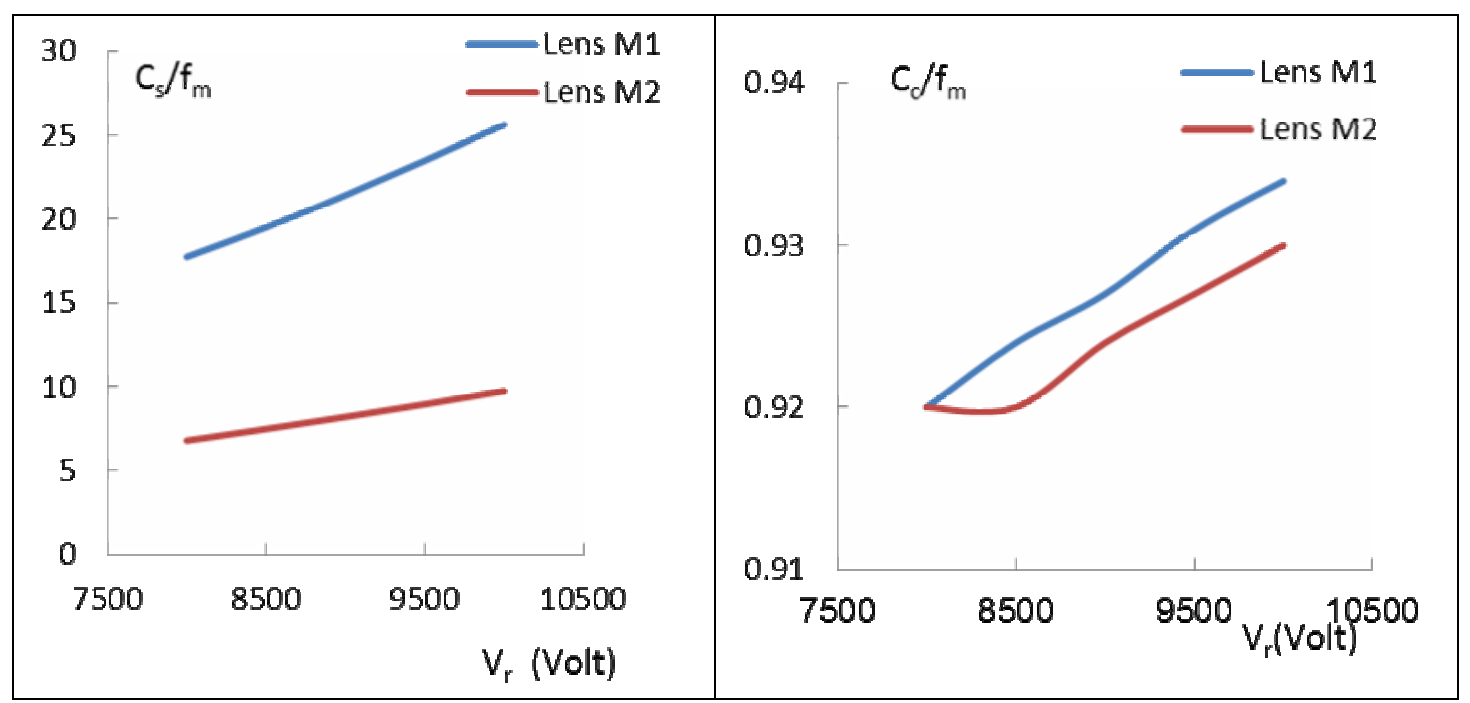

Fig. 5: Variations of the relative spherical aberration coefficients $\left(C_{s} / f_{m}\right)$ and the relative chromatic aberration coefficients $\left(\mathrm{C}_{\mathrm{c}} / \mathbf{f}_{\mathrm{m}}\right)$ as a function of relativistically- corrected accelerating voltage $V_{r}$.

It can be noticed from the above results lens M2 with soft iron insulation is better than that of lens M1 with air insulation because it has lower values of aberration coefficients and higher magnetic flux density peak. 


\section{B. The Electrostatic Lens Design Consideration}

Electrostatic lenses are widely used to control the beams of charged particle with various energy and directions in several fields, especially in the electron microscopy (Al-Khashab and AlShamma, 2009).

Three types of asymmetrical electrostatic lenses denoted by (E1, E2 and E3) have been designed in order to examine the effect of the outer electrode geometry on the two- coaxial cylinder electrostatic lens. The inner (small diameter) cylinder represents the first electrode (I) was chosen of constant value of the length $(\mathrm{L}=10 \mathrm{~mm})$ and at voltage $\left(\mathrm{V}_{\mathrm{I}}=8000\right.$ Volt). While the outer (larger diameter) cylinder representing the second electrode (II) was chosen of different shapes geometrics, and accelerated at various voltages range $\left[\mathrm{V}_{\mathrm{II}}=(100-1000) \mathrm{V}\right]$ as denoted in (Fig. 6).

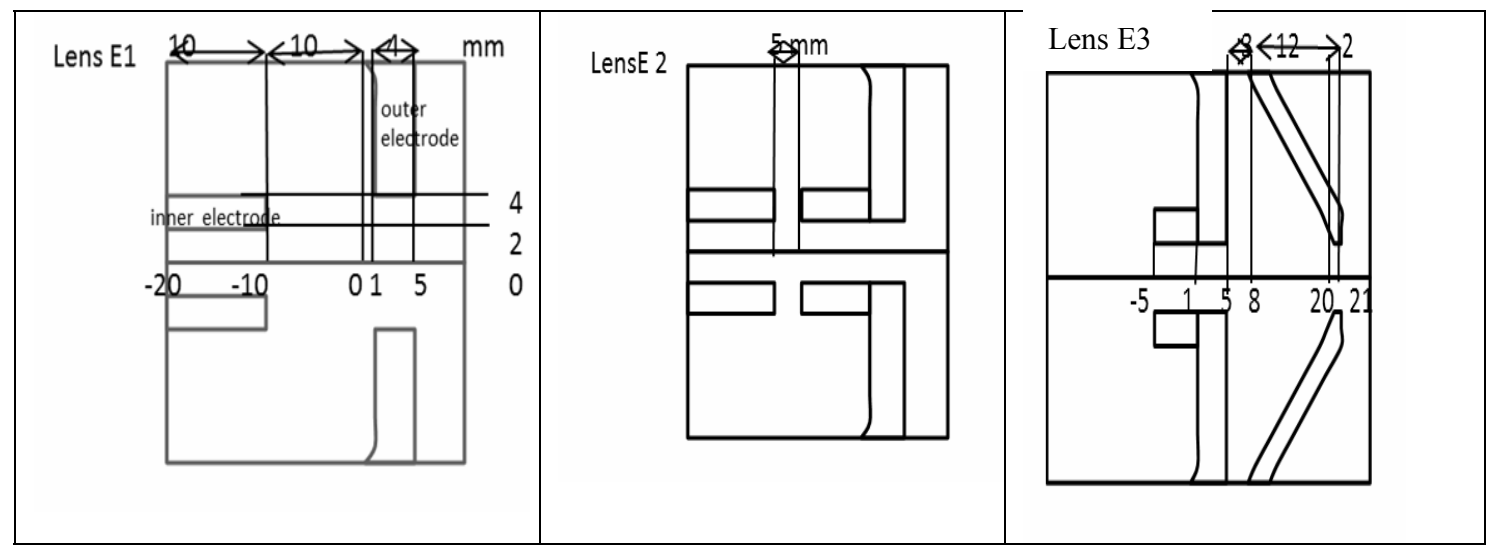

Fig. 6: Cross-section of the asymmetrical two-coaxial cylinders electrostatic lenses (E1-E3) with different shapes of the outer electrode.

The axial potential distribution of the asymmetrical electrostatic lenses E1, E2 and E3, are calculated by the aid of Munro's program E11 using the finite element. The axial potential distributions $\mathrm{V}_{\mathrm{z}}$ of the above lenses are calculated at voltages $\left(\mathrm{V}_{\mathrm{I}}=8000 \mathrm{~V}\right)$ and $\left(\mathrm{V}_{\mathrm{II}}=100 \mathrm{~V}\right)$ as illustrated in (Fig. 7). This figure shows that the gradient of the axial potential distributions of the lens E2 decreases rapidly compared with that of the other lenses (E1 and E3). This leads to the best electron optical properties. Moreover, it is important to calculat the trajectories of the electrons in the structure of these lenses in order to compare their performance. The trajectories ray $R_{z}$ are calculated using the program E21 (Munro, 1975). It should be noticed from (Fig. 8) that the lens E2 has acquired a lowest working distance (W.D.) which in turn, gives a good performance of the optical properties.

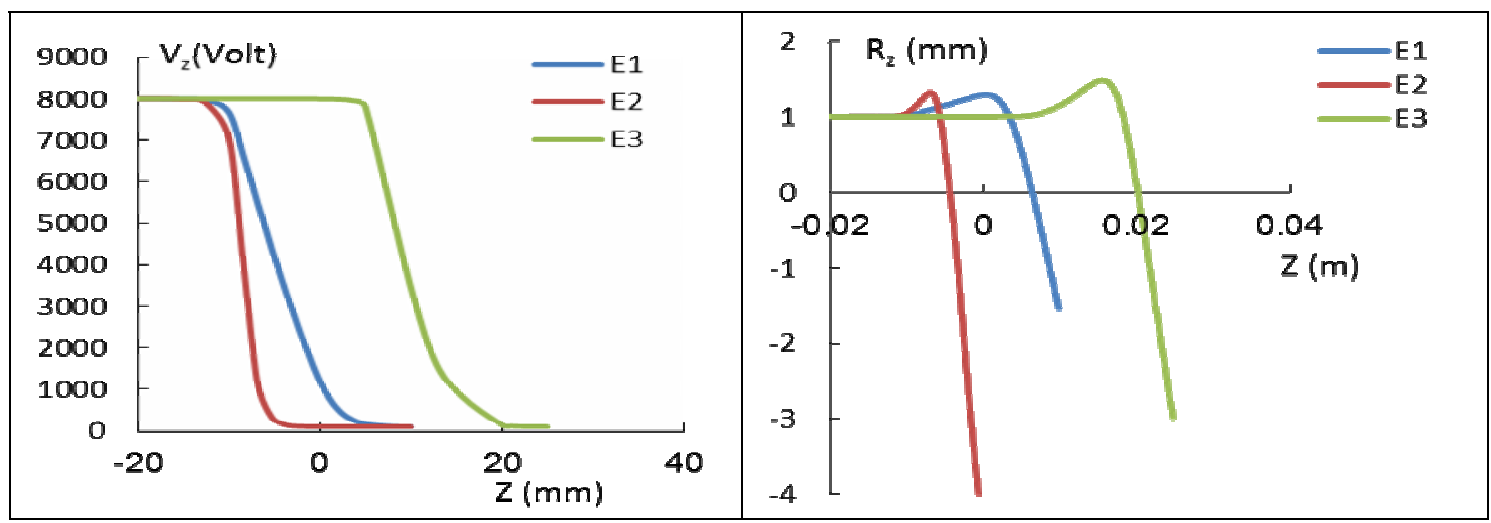

Fig. 7: Axial potential distribution of the Fig. 8: Trajectories of the electrons inside electrostatic lenses (E1-E3) at constant voltage $\left(\mathrm{V}_{\mathrm{I}}=\mathbf{8 0 0 0} \mathrm{V} ; \mathrm{V}_{\mathrm{II}}=\right.$ the electrostatic lenses (E1-E3), at constant voltage $\left(\mathrm{V}_{\mathrm{I}}=\mathbf{8 0 0 0} \mathrm{V} ; \mathrm{V}_{\mathrm{II}}=\right.$ $100 \mathrm{~V})$. 100V). 
The equipotential lines of these lenses were calculated by using the program E31 (Munro, 1975) which has been modified by (Hujazie, 2006). It can be seen from (Fig. 9) that the effect of the outer electrode geometry has a clear effect on the equipotential lines of the electric field. It is noticed that the equipotential lines are more converging round the optical axis as occurred in the lens E2 than that of the other lenses.

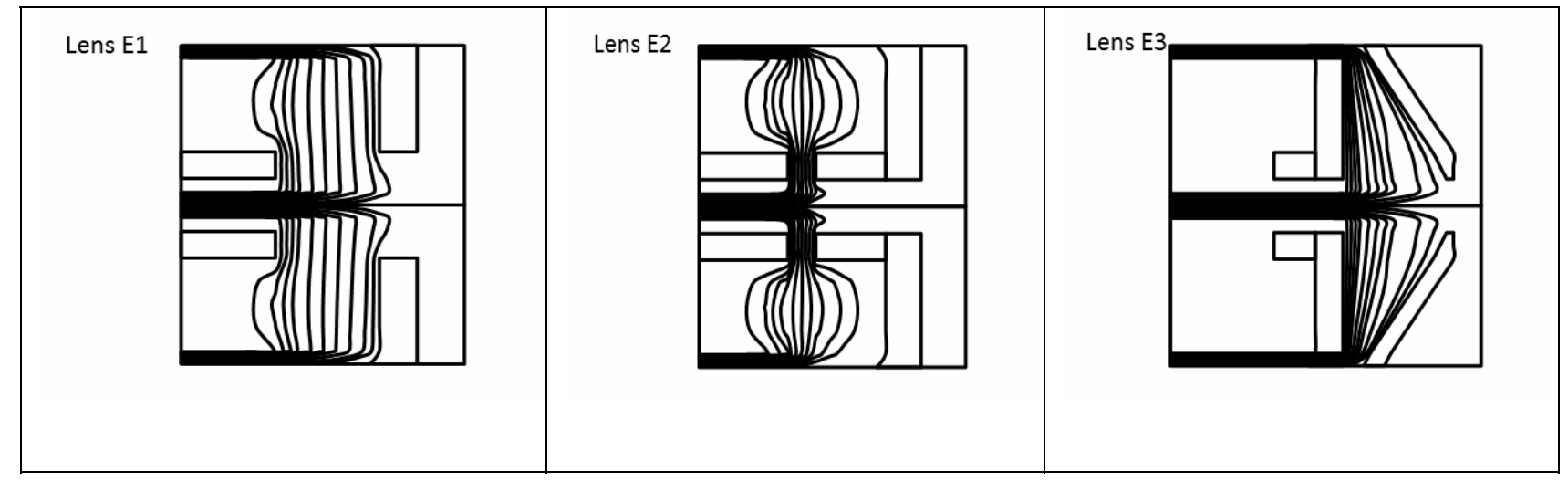

Fig. 9: Equipotential lines of the electrostatic lenses (E1- E3) at the same constant voltages.

The electron optical properties of these lenses were calculated by using Munro program E21. (Fig. 10) illustrates the variation of the relative spherical and chromatic aberration coefficients $\left(\mathrm{C}_{\mathrm{s}} / \mathrm{f}_{\mathrm{e}}\right.$ and $\mathrm{C}_{\mathrm{c}} / \mathrm{f}_{\mathrm{e}}$ ) of the electrostatic lenses as a function of the final beam voltage $\mathrm{V}_{\text {II. }}$ This figure shows that the lens E2 has the relatively lower electron optical properties values in comparison with that of the other lenses. Thus, the lens E2 can be regarded as the best or preferable lens compared with other lenses.

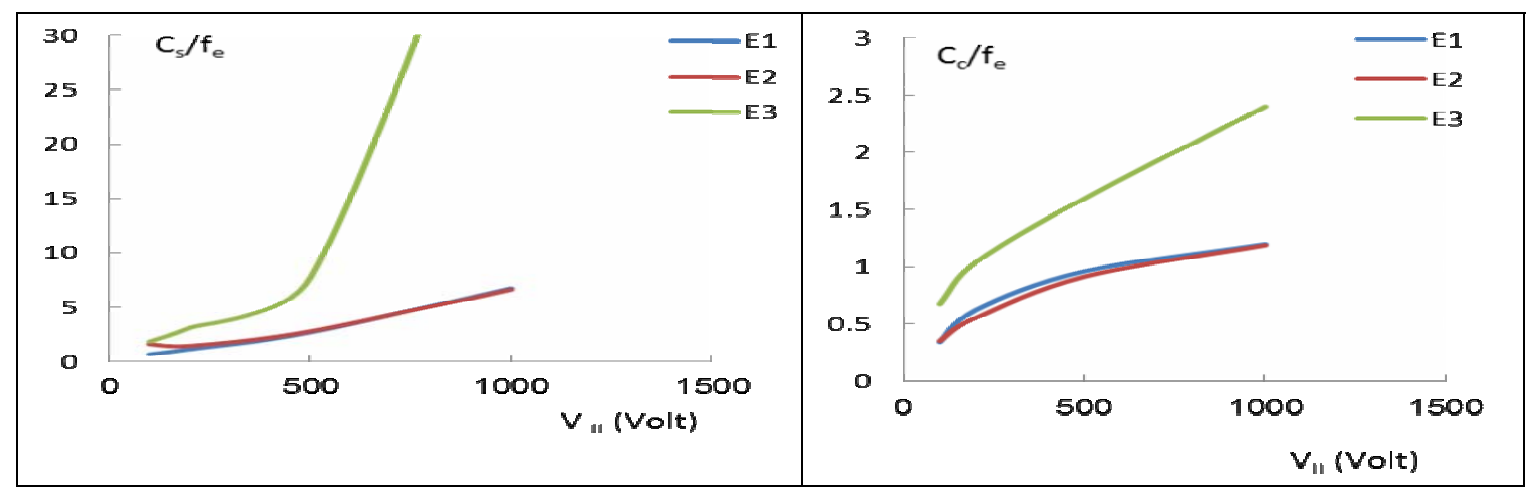

Fig. 10: Varation of the relative spherical aberration coefficients $\left(C_{s} / f_{e}\right)$ and the relative chromatic aberration coefficients $\left(C_{c} / f_{e}\right)$ as a function of final beam voltage $V_{I I}$, $\left(\mathrm{V}_{\mathrm{I}}=\mathbf{8 0 0 0} \mathrm{V}\right)$.

\section{The Compound (Magnetic - Electrostatic) Lens Design Consideration.}

A combination of asymmetrical magnetic lens (M2) which possesses a preferable design previously obtained in part A, and asymmetrical two- coaxial cylinder electrostatic lens with an external conical shape (lens E2) acquires a best lens design as previously obtained in part B as shown in (Fig. 11). The electrostatic lens is located inside the magnetic lens. The electron beam is accelerated to a high potential more than $8000 \mathrm{~V}$ in the full length of the column. In a small gap round the polepiece region, the primary electrons are retarded to the selected beam energy, may be 
as low as $100 \mathrm{eV}$ (i.e toward the second electrode of the electrostatic lens II). (Al- Khashab, and Hujazie, 2011).

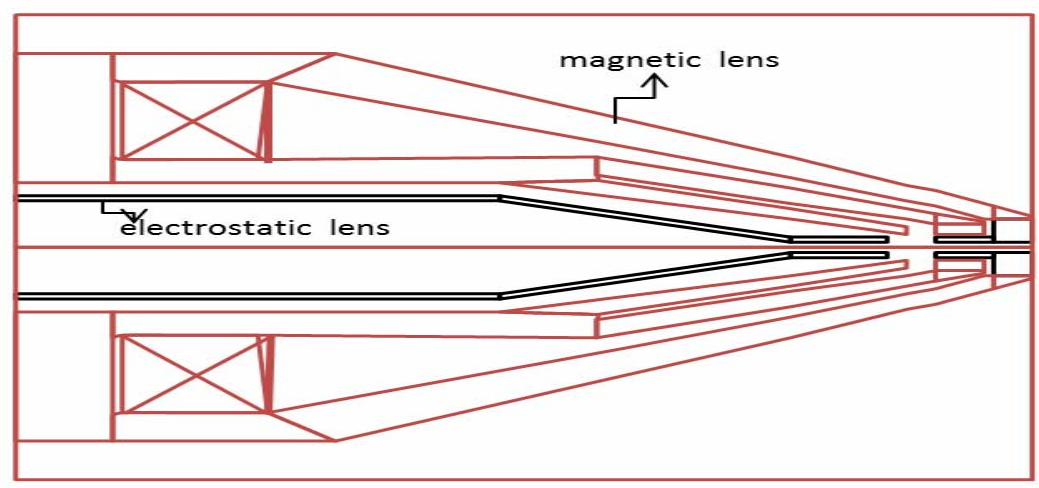

Fig. 11: Schematic diagram of the compound magnetic M1 and electrostatic E2 lenses.

From the previous results of the axial magnetic flux density distribution $B_{z}$ of lens $\mathrm{M} 2$ at excitation $(\mathrm{NI}=500 \mathrm{~A}-\mathrm{t})$ and the axial potential distribution $\mathrm{V}_{\mathrm{Z}}$ of lens $\mathrm{E} 2$ at $\left(\mathrm{V}_{\mathrm{I}}=8000 \mathrm{~V}\right.$ and $V_{I I}=100 \mathrm{~V}$ ) is taken along the complete range from $Z=-40 \mathrm{~mm}$ to $Z=20 \mathrm{~mm}$ is indicated in (Fig. 12) which shows that there is an interception of both curves at $Z<-5 \mathrm{~mm}$ due to the retardation effect of the electrons beam.

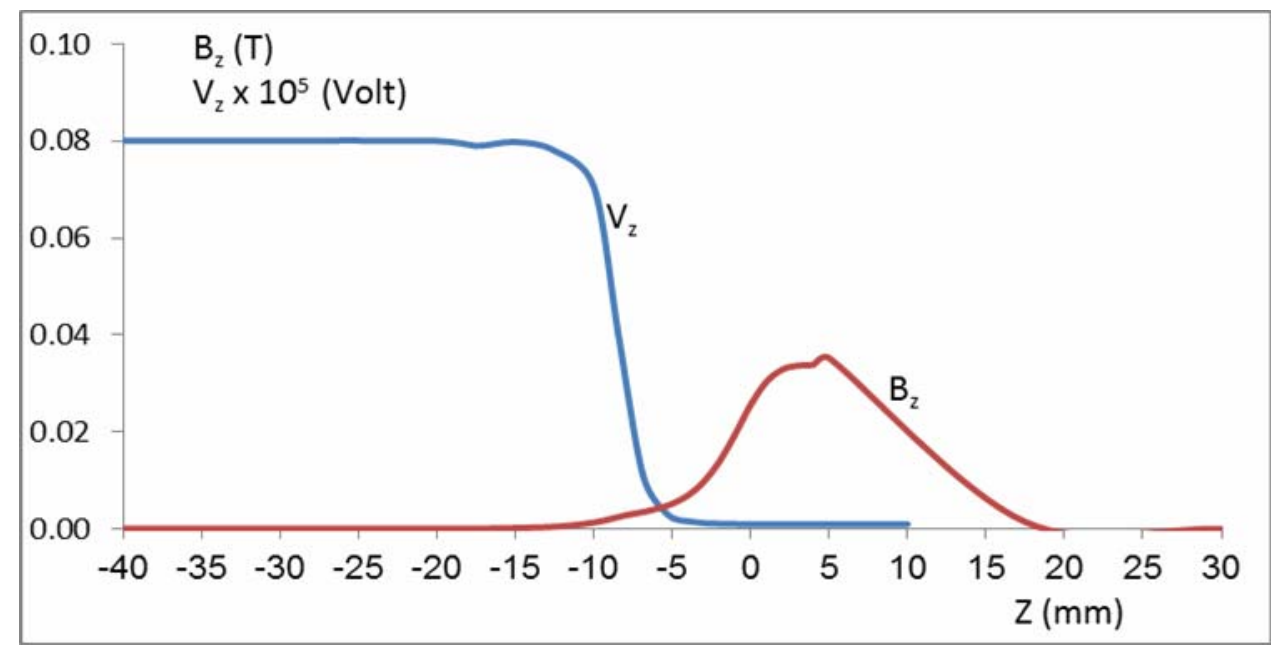

Fig. 12: Axial magnetic flux density distribution $B_{z}$ of the magnetic lens $M 2$ at excitation (NI= 500 A-t) together with the axial potential distribution $V_{z}$ of the electrostatic lens (E2) at constant voltages $\left(\mathrm{V}_{\mathrm{I}}=\mathbf{8 0 0 0} \mathrm{V} ; \mathrm{V}_{\mathrm{II}}=\mathbf{1 0 0} \mathrm{V}\right)$.

The trajectory $R_{z}$ of the electrons beam inside the structure of the compound lens is plotted as a function of the distance $(Z)$ as shown in (Fig. 13). It is clear from this figure that in the combined mode, the focusing is more complex, the trajectory $R_{z}$ is first refracted towards the axis by the effect of the convergent magnetic lens and then refracted away by the divergent lens of the electrostatic doublet in order to be finally focused on by its convergent part. 


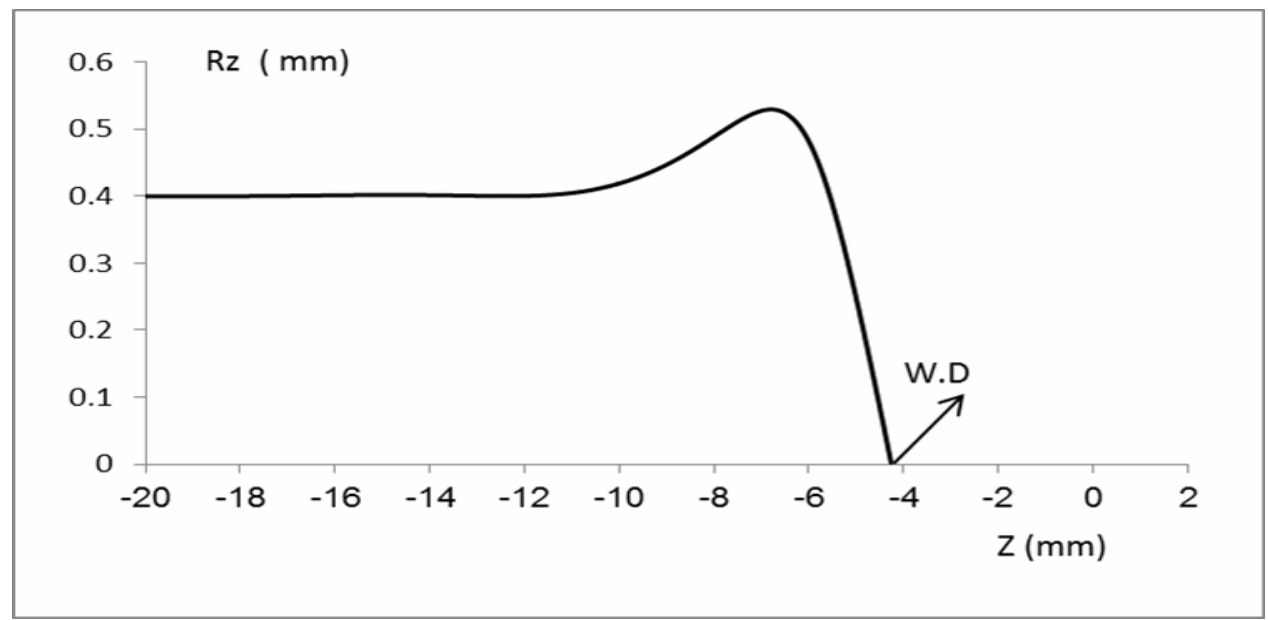

Fig. 13: Trajectory of the electrons beam $R_{Z}$ inside the structure of the compound lens as a function of the distance $(\mathrm{Z})$.

The computed results of the objective focal properties of the compound lens recorded very lower values in the aberration coefficients $\left(\mathrm{f}_{\mathrm{c}}=2.84 \mathrm{~mm}, \mathrm{C}_{\mathrm{s}}=9.79 \mathrm{~mm}\right.$ and $\left.\mathrm{C}_{\mathrm{c}}=0.77 \mathrm{~mm}\right)$ while the values of the aberration coefficient of the purely magnetic lens equals $\left(\mathrm{f}_{\mathrm{m}}=28.28 \mathrm{~mm}, \mathrm{C}_{\mathrm{s}}=193.26\right.$ $\mathrm{mm}$ and $\left.\mathrm{C}_{\mathrm{c}}=25.92 \mathrm{~mm}\right)$, which lead to give the compound lens a good resolving power $(\delta=1.0 \mathrm{~nm})$ at low beam energies compared with the resolving power of the pure magnetic lens $(\delta=1.47 \mathrm{~nm})$.

It is important to compare between the trajectories ray of the electron inside the asymmetrical purely magnetic lens with that of the compound lens as shown in (Fig. 14). From this comparison, the trajectories ray $\mathrm{R}_{\mathrm{z}}$ for the purely magnetic mode has a further large distance from the optical axis, while in the combined magnetic- electrostatic mode the focusing is obtained near the optical axis. Consequently, this lens has the working distance smaller in value compared with that of the purely magnetic lens.

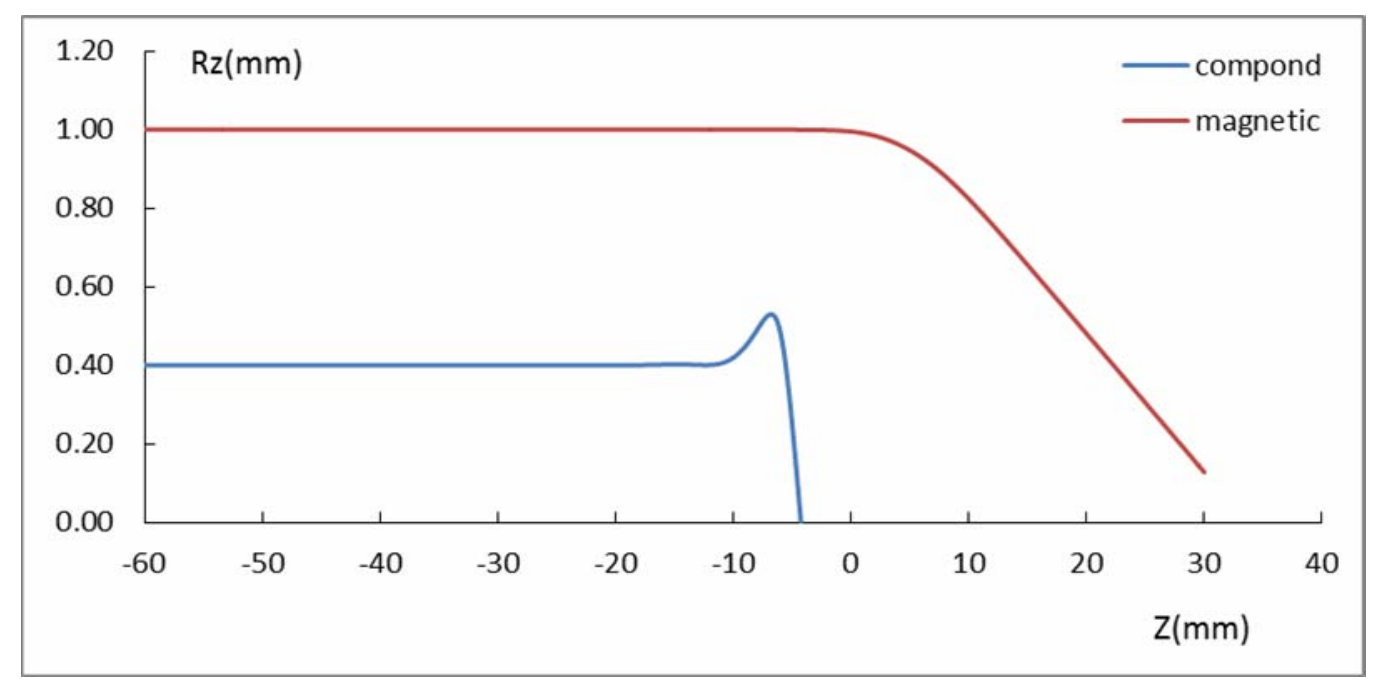

Fig. 14: Comparison between the trajectory of the electron beam inside the purely magnetic lens and the compound lens as a function of distance $Z$.

\section{Comparison with Other Works}

It is necessary to make a comparison between the objective focal properties of the above compound lens (present work) with the other recently published results as illustrated in Table (1). 
Table 1: Comparison between the optical properties of the compound lens (present work) with these of published results (other researchers)

\begin{tabular}{|l|l|l|l|l|l|}
\hline Researchers & $\mathbf{V}_{\mathbf{I}}(\mathbf{v o l t})$ & $\mathbf{V}_{\text {II }}($ Volt) & $\mathbf{f}_{\mathbf{c}}(\mathbf{m m})$ & $\mathbf{C}_{\mathbf{s}}(\mathbf{m m})$ & $\mathbf{C}_{\mathbf{c}}(\mathbf{m m})$ \\
\hline Present work & 8000 & 100 & 2.84 & 9.79 & 0.77 \\
\hline Yonezawa et al., 2003 & 1000 & --------- & ------- & ------- & 0.6 \\
\hline Al- Jumayli, 2010 & 10000 & 100 & 7.81 & 0.05 & 1.6 \\
\hline $\begin{array}{l}\text { Al-Khashab and Hujazie, } \\
\text { 2011 }\end{array}$ & 8000 & 100 & 11.31 & 0.92 & 0.7 \\
\hline Muray, 2011 & 1000 & --------- & 7.5 & 9.9 & 2.6 \\
\hline
\end{tabular}

\section{CONCLUSION}

The first conclusion from the previous analysis is that the asymmetrical magnetic electron lens with soft iron insulation in the polepiece is better than that of lens with air insulation in the polepiece because it has lower values of aberration coefficients.

The second conclusion is related to the asymmetrical two - coaxial over lapping cylinder electrostatic lenses, the geometrical shape of the outer electrode has a great effect on the axial potential distribution and on the electron optical properties.

Finally, the magnetic/ electrostatic lens combination is equivalent to an optical triplet lens which increases the incident beam aperture angle at the specimen and hence improves the resolution. The analysis and calculation results have shown that the magnetic and electrostatic retarding field has produced an excellent electron - optical performance.

\section{REFERENCES}

Al- Khashab, M.A.; Hujazie, N.S. (2011). The electron optical performance of the Gemini lens design for a low voltage scanning electron microscope. Dirasat, Pure Sci., 38(1), 52- 60.

Al- Jumayli, F.A. (2010). Design and fabrication a chroma corrected objective compound lens for low beam energies for scanning electron microscope. Ph.D. Thesis, The University of Mosul in Mosul, Iraq (in Arabic).

Al- Khashab, M.A.; Al-Shamma, M.T. (2009). The effect of Multi- electrodes on the optical performance of electrostatic immersion lenses. Dirasat, Pure Sci., 36 (2), 171- 182.

Al- Khashab, M.A.; Ahmad, A.H. (2005). Designing a doublet lens of optimized polepiece angle. Dirasat, Pure Sci., 32(2), 182 - 188.

Drexel, V.; Weimer, E.; Martin, J.P. (1994). Ultra - high resolution colum for the scanning electron microscope. Proc. MSACEds. Bailey GW, Garrett- Reed A J. San Francisco press, 486- 487.

Frosien, J.; Plies, E.; Anger, K. (1989). Compound magnetic and electrostatic lenses for lowvoltage applications. J. Vac. Sci. Techno., B7(6), 1874- 1877.

Hujazie, N.W. (2006). Design of compound magnetic - electrostatic lens for low voltage scanning electron microscope, Ph.D. Thesis, Mosul University, Iraq.

Jingy, Z., Tiantong, T., Yong, F.; Wenjun, S.(2012). Study on rotation - free combined immersion magneto-electrostatic lenses. Optik, 123, 1233 - 1235.

Lencova', B. (1986). Program AMAG for computation of vector potential in rotationally symmetric magnetic electron lenses by FEM. Inst. Sci, Brono, Czechoslovakia, 1- 58.

Lencova', B.; Lenc, M. (1994). Computation of properties of electrostatic lenses. Optik, 97(3), 121126. 
Mulvey, T. (1982). "Unconventional Lens Design, in Magnetic Electron Lenses". P.W. Hawkes, ed., Springer - Verlag, Berlin, pp. 359- 420.

Munro, E. (1975). "A Set of Computer Programs for Calculating the Properties of Electron Lenses". Cambridge University, Eng., Dept., Report CUED/ B- ELECT/ TR. 45 p.

Murad, W.M. (1998). Design of iron- free magnetic electron lenses. M.Sc. Thesis, The University of Mosul, Iraq (in Arabic)

Muray, L.P. (2011). "Low- Voltage Microscopy Instrumentation". Agilent Technologies, Santa Clara, California, SCANNING, V. 33, pp. 155-161.

Tromp, R.M. (2000). Low- energy electron microscopy. IBM J. Research and Development, Emerging Analytical Techniques. 44(4).

Van Bree, P.J.; Van Lierop, C.M.; Van den Bosch, P.J. (2009). Control - oriented hysteresis models for magnetic electron lenses. Eindhoven University of Technology, Nether Lands, Iee Transactions On Magnetics, 45(11), 5235 - 5238.

Wen- ping, Wu Jian; Zhou zhen; Gui li- jiang; Han li, (2009). Practical integrated design of a condenser-objective lens for transmission electron microscope. J. Physics. Conference Series, $188,1-5$.

Yonezawa, A.; Maruo, M.; Takeuchi, T.; Morita, S.; Noguchi, A.; Takooka, O.; Sato, M.; Wannberg, B. (2003). Single polepiece objective lens with electrostatic bipotantial lens for SEM. J. Electron Microscopy, 51, 149- 156.

Young, J. (2004). LEO 982 field emission SEM. Anatine user facility for the scientific community web master@ensi.poi.gov. 